\title{
TUNING OF PID CONTROLLER BASED AGC SYSTEM USING GENETIC ALGORITHMS
}

\author{
Ravindra Singh, Indraneel Sen \\ Department of Electrical Engineering \\ Indian Institute of Science \\ Bangalore-560012, INDIA \\ rsingh@ee.iisc.ernet.in, sen@ee.iisc.ernet.in
}

\begin{abstract}
This paper deals with the tuning of AGC of an interconnected power system using genetic algorithms (GA). A two area AGC system is considered for study and both the areas are considered to be equipped with PID controllers. Parameters of these PID controllers are obtained using a novel genetic algorithm based optimization technique. For comparison, the same parameters are also tuned using the Ziegler-Nichols method. The performance of the proposed controller has been compared with the performance of the conventional integral controller in order to demonstrate the superiority of the proposed GA Based PID controller.
\end{abstract}

Index Terms: Automatic Generation Control (AGC), Genetic Algorithms, PID Controller, Two Area System.

\section{INTRODUCTION}

In large interconnected power systems, It is practically impossible to run all the generators at synchronous speed all times, hence for satisfactory operation of power system, the frequency should remain nearly constant. Relatively close control of frequency ensures constancy of speed of generators.

In an interconnected system with two or more independently controlled areas, in addition to control of frequency, the generation within each area has to be controlled so as to maintain scheduled power interchange. For an interconnected multi-area system, to maintain the balance between the load and generation in each area, the controller should maintain [1]

1. Frequency at scheduled value

2. Net interchange power with neighbouring areas at the scheduled values.

Several methods are available for designing AGC controllers. The simplest one is application of integral control action to minimize the area control error [1], [2]. With advancement in control technology several other control methods have been proposed to provide better AGC systems. These methods are based on modern control theory [3], [4], Neural network [5], [6], [7] and Fuzzy system theory [8], [9].
Recently genetic algorithms are widely being used for control system design. In this paper an attempt has been made to design AGC system using genetic algorithms. PID controller structure is considered and its parameters are obtained using GA.

The basic operating principles of GAs [10-13] are based on the principles of natural evolution. There are many variations of the genetic algorithms but the basic form is simple genetic algorithm (SGA). This algorithm works with a set of population of candidate solution represented as strings. The initial population consists of randomly generated individuals. At every iteration of the algorithm, fitness of each individual in current population is computed. The population is then transformed in stages to yield a new current population for next iteration. The transformation is usually done in three stages by simply applying the following genetic operators: (1) Selection, (2) crossover, and (3) mutation. In the first stage selection operator is applied as many times as there are individuals in the population. In this stage every individual is replicated with a probability proportional to its relative fitness in the population. In the next stage, the crossover operator is applied. Two individuals (Parents) are chosen and combined to produce two new individuals. The combination is done by choosing at random a cutting point at which each of parents is divided into two parts; these are exchanged to form the two offspring which replace their parents in the population. In the final stage, the mutation operator changes the values in a randomly chosen location on an individual. The algorithm terminates after a fixed number of iterations and the best individual generated during the run is taken as the solution.

\section{PROBLEM FORMULATION}

\subsection{System Representation}

Figure 1 shows the schematic of a two area system considered for the study. The system parameters are given in Appendix I. State space model representing the dynamics of this system can be given by:

$$
\dot{x}=A x+B u+F w
$$




$$
\begin{array}{r}
x^{t}=\left[\Delta f_{1} \Delta P_{G 1} \Delta x_{g o v 1} \Delta f_{2} \Delta P_{G 2} \Delta x_{g o v 2}\right. \\
\left.\Delta P_{t i e 1} \Delta x_{i n t 1} \Delta x_{i n t 2}\right] \\
u^{t}=\left[\Delta P_{C 1} \Delta P_{C 2}\right], \quad w^{t}=\left[\Delta P_{D 1} \Delta P_{D 2}\right]
\end{array}
$$

Description of various terms is given in Ref.[2] and matrices $A, B$ and $F$ are defined in Appendix II.

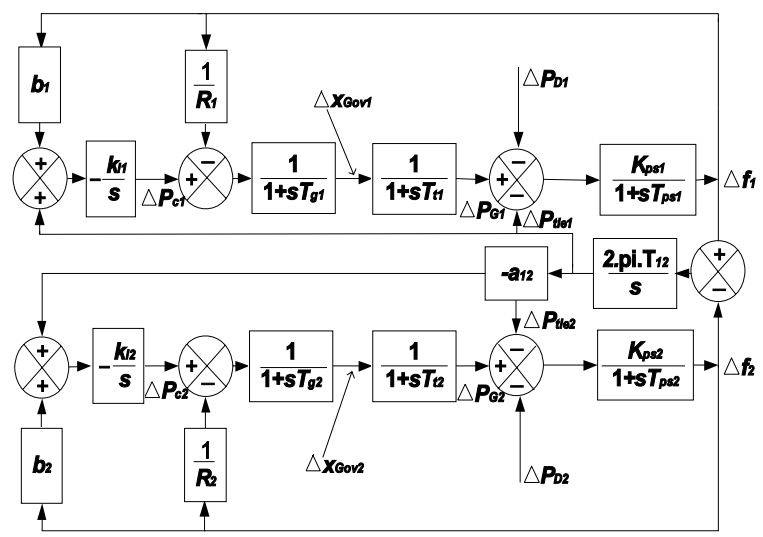

Fig. 1. Two area AGC system with integral control

In the two area system considered for study, the conventional integral controller was replaced by a PID controller with the following structure [14].

$$
G_{c}(s)=K p\left(1+\frac{1}{T_{i} s}+T_{d} s\right)
$$

Where $K_{p}$ is proportional gain. $T_{i}$ and $T_{d}$ are integral and derivative time constants respectively. The PID controllers in both the areas were considered to be identical.

\subsection{Objective Function}

In a multiarea system the area control error for the $i_{t h}$ area is defined as:

$$
A C E_{i}=\Delta P_{t i e, i}+b_{i} \Delta f_{i}
$$

Now a performance index can be defined by adding the sum of squares of cumulative errors in ACE, hence based on area control error a performance index $J$ can be defined as:

$$
J=\int_{0}^{\infty} \sum_{i=1}^{2}\left(A C E_{i}\right)^{2} d t
$$

Based on this performance index $J$ optimization problem can be stated as:

\section{Minimize $J$}

Subjected to:

$$
\begin{aligned}
& K_{P, j}^{\min } \leq K_{P, j} \leq K_{P, j}^{\max } \\
& T_{i, j}^{m i n} \leq T_{i, j} \leq T_{i, j}^{m a x} \\
& T_{d, j}^{m i n} \leq T_{d, j} \leq T_{d, j}^{m a x} \\
& \quad j=1,2
\end{aligned}
$$

$K_{P, j}, T_{i, j}$ and $T_{d, j}$ are PID controller parameters of $j_{\text {th }}$ area.

\section{PARAMETER SELECTION}

\subsection{Conventional Ziegler-Nichols Rule Based Tun- ing [14]}

The parameters of the PID controller were obtained using genetic algorithms. For the comparison the PID controller was also tuned using conventional ZieglerNichols tuning rule based on critical gain $K_{c r}$ and critical period $P_{c r}$. Values of $K_{c r}$ and $P_{c r}$ were calculated from the sustained oscillations [Figure 2] of the output by employing only proportional controller. As shown in Figure 2, value of $P_{c r}$ for a critical gain $K_{c r}=0.978$ is 2.85 . This method gives

$$
G_{c}(s)^{c o n v}=0.5868\left(1+\frac{1}{1.425 s}+0.3563 s\right)
$$

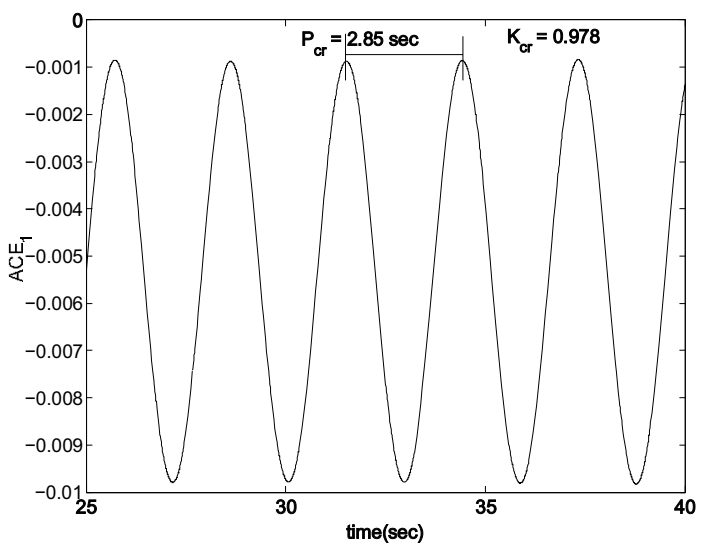

Fig. 2. System response with only proportional controller under critical gain

\subsection{GA Based Tuning}

In the GA routine parameters $K_{p, j}, T_{i, j}$ and $T_{d, j}(j=$ $1,2)$ were taken as control variables. These parameters were obtained simultaneously by solving the the constrained optimization problem given in section $\mathbf{2 . 2}$ using genetic algorithm. The GA was run for 200 generations with a population size of 500 . Probability of crossover and mutation were taken as 0.85 and 0.033 .

Flow chart shown in Figure 3 gives the schematic of GA process for tuning the PID controller parameters for AGC system.

Optimal parameters obtained after a complete GA run are shown in Table 1.

Table 1. Optimal controller parameters after GA run

\begin{tabular}{|l||c|c|c|}
\hline & $K_{P}$ & $T_{i}(\mathrm{sec})$ & $T_{d}(\mathrm{sec})$ \\
\hline Area $_{1}$ & 21.5604 & 3.1916 & 0.9011 \\
Area $_{2}$ & 21.5604 & 3.1916 & 0.9011 \\
\hline
\end{tabular}




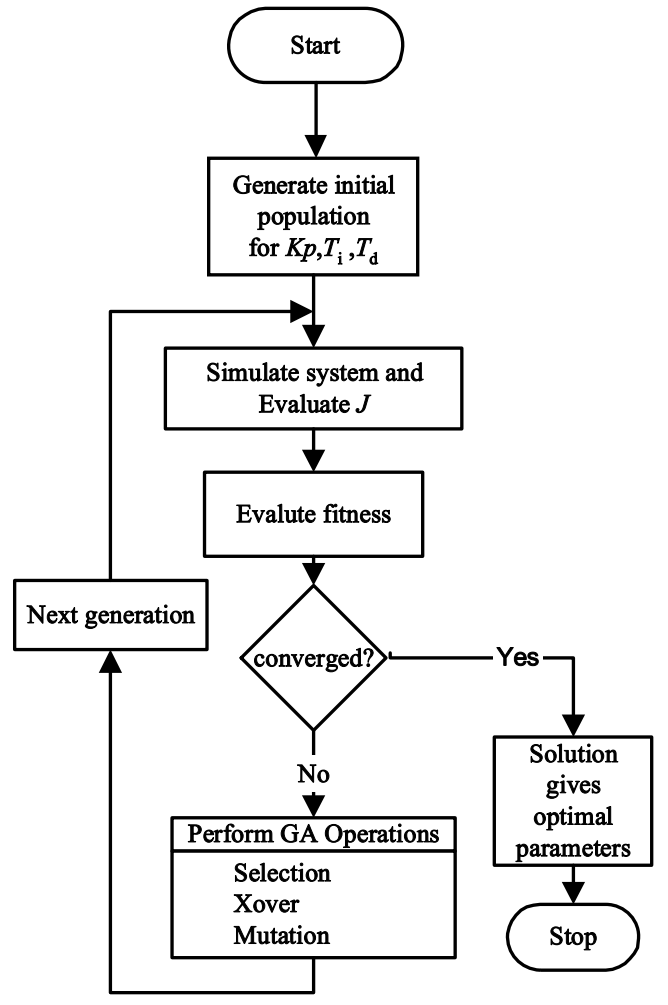

Fig. 3. Flow chart for the GA process

\section{PERFORMANCE EVAlUATION}

Performance of the GA based controller was compared with the conventionally tuned PID controller given by Equation 6. Its performance was also compared with conventional integral controller used for AGC. The gain of this integral controller was taken as 0.09 for both the areas.

\subsection{Time Domain Simulation}

Figures 4, 5, and 6 show the time domain performance of the AGC system with GA tuned controller. System was simulated for 20 seconds with step change of $0.1 \mathrm{pu}$ in load of area 1. Disturbance was given at $t=1.0 \mathrm{sec}$. Time response with conventional integral controller and conventional PID controller are also plotted.

As seen, the GA tuned controller gives better performance in terms of overshoot and settling time. With the GA based controller oscillations are damped out within two seconds. This shows the efficacy of the GA tuned PID controller over conventionally tuned PID controller.

\subsection{Computational Requirements}

The GA based PID controller tuning performed on two area AGC system was done on a Pentium-III PC, using a program coded in MATLAB 6.1. The CPU time spent in one generation of GA was approximately 2 minutes on an average. Most of the time was spent in system simulation and evaluation of fitness.
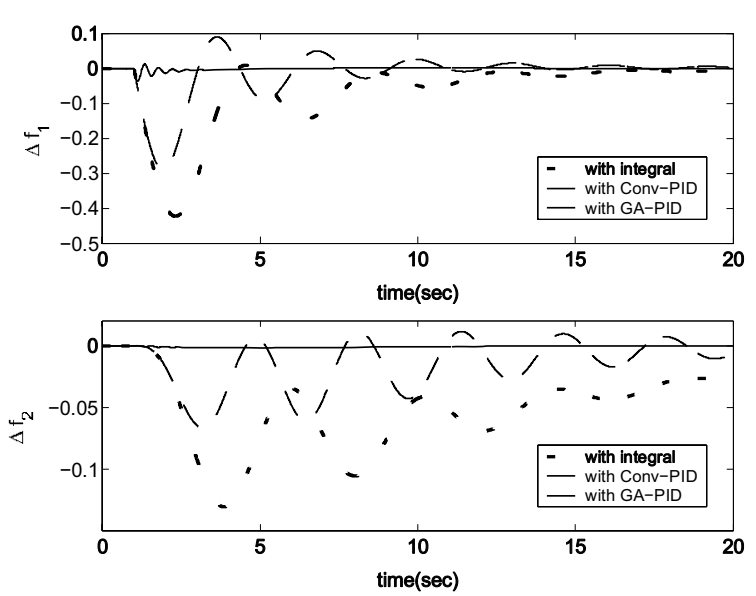

Fig. 4. Variation of frequencies due to step change in load $\left(\Delta P_{D 1}=0.1 \mathrm{pu}\right)$ in area 1
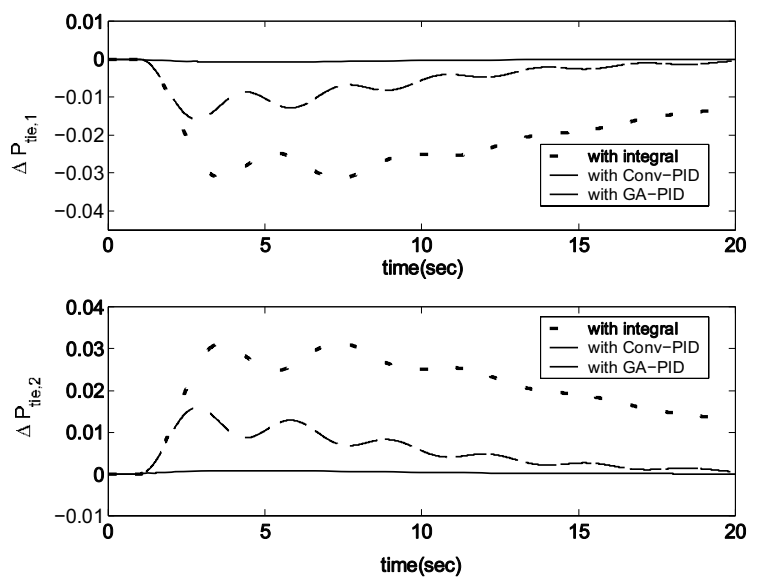

Fig. 5. Variation of tie-line powers due to step change in load $\left(\Delta P_{D 1}=0.1 \mathrm{pu}\right)$ in area 1
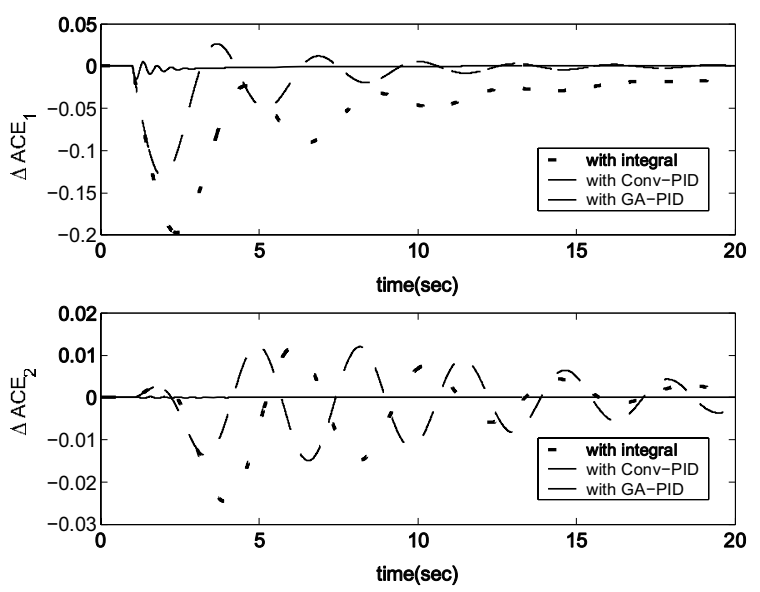

Fig. 6. Variation of area control errors due to step change in load $\left(\Delta P_{D 1}=0.1 \mathrm{pu}\right)$ in area 1

\section{CONCLUSIONS}

The results presented in this paper show that genetic algorithm techniques could be used for designing more efficient AGC controllers. The advantage of GA technique is that it is independent of the complexity of per- 
formance index considered. Performance evaluation of the GA based controller on a two area system shows that its performance is far better than that could be obtained by conventionally tuned controller. In addition, the design procedure is simple and bears much potential for practical implementation.

\section{APPENDIX I}

\section{SYSTEM DATA}

$T_{s g 1}=T_{s g 2}=0.4 \mathrm{sec}, T_{t 1}=T_{t 2}=0.5 \mathrm{sec}$, $T_{p s 1}=T_{p s 2}=20 \mathrm{sec}, K_{p s 1}=K_{p s 2}=100$, $R_{1}=R_{2}=3, \quad b_{1}=b_{2}=0.425, \quad 2 \pi T_{12}=0.05$, $a_{12}=1$.

\section{APPENDIX II}

\section{MATRICES A, B AND F OF SECTION 2.1}

$A=$

$$
\left[\begin{array}{ccccccccc}
-\frac{1}{T_{p s 1}} & \frac{K_{p s 1}}{T_{p s 1}} & 0 & 0 & 0 & 0 & -\frac{K_{p s 1}}{T_{p s 1}} & 0 & 0 \\
0 & -\frac{1}{T_{t 1}} & \frac{1}{T_{t 1}} & 0 & 0 & 0 & 0 & 0 & 0 \\
-\frac{1}{R_{1} T_{s g 1}} & 0 & -\frac{1}{T_{s g 1}} & 0 & 0 & 0 & 0 & 0 & 0 \\
0 & 0 & 0-\frac{1}{T_{p s 2}} & \frac{K_{p s 2}}{T_{p s 2}} & 0 & \frac{a_{12} K_{p s 2}}{T_{p s 2}} & 0 & 0 \\
0 & 0 & 0 & 0 & -\frac{1}{T_{t 2}} & \frac{1}{T_{t 2}} & 0 & 0 & 0 \\
0 & 0 & 0-\frac{1}{R_{2} T_{s g 2}} & 0-\frac{1}{T_{s g 2}} & 0 & 0 & 0 \\
2 \pi l_{12}^{\prime} & 0 & 0-2 \pi T_{12}^{1} & 0 & 0 & 0 & 0 & 0 \\
b_{1} & 0 & 0 & 0 & 0 & 0 & 1 & 0 & 0 \\
0 & 0 & 0 & b_{2} & 0 & 0 & -a_{12} & 0 & 0
\end{array}\right]
$$

$$
B=\left[\begin{array}{cc}
0 & 0 \\
0 & 0 \\
\frac{1}{T_{s g 1}} & 0 \\
0 & 0 \\
0 & 0 \\
0 & \frac{1}{T_{s g 2}} \\
0 & 0 \\
0 & 0 \\
0 & 0
\end{array}\right], F=\left[\begin{array}{cc}
-\frac{K_{p s 1}}{T_{p s 1}} & 0 \\
0 & 0 \\
0 & 0 \\
0 & -\frac{K_{p s 2}}{T_{p s 2}} \\
0 & 0 \\
0 & 0 \\
0 & 0 \\
0 & 0 \\
0 & 0
\end{array}\right]
$$

\section{REFERENCES}

[1] P. Kundur, Power System Stability and Control, McGraw-Hill, Inc., 1994.

[2] I.J. Nagrath and D.P. Kothari, "Modern Power System Analysis", Tata McGraw-Hill Publishing Company Ltd., New Delhi, 2000.

[3] M.L. Kothari, J. Nanda, D.P. Kothari, and D.Das, "Discrete Mode AGC of a Two Area Reheat Thermal System With New ACE," IEEE Transactions on Power Systems, Vol. 4, pp. 730-738, May 1989.

[4] R.R. Shoults and J.A. Jativa, "Multi Area Adaptive LFC Devloped For a Comprehensive AGC Simulator," IEEE Transactions on Power Systems, Vol. 8, pp. 541$547,1993$.
[5] Q.H. Wu, B.W. Hogg, and G.W. Irwin , "A Neural Network Regulator For Turbo Generator," IEEE Transactions on Neural Networks, Vol.3, pp. 95-100, 1992.

[6] D.K. Chaturvedi, P.S. Satsangi, and P.K. Kalra, "Load Frequency Control: A Genaralised Neural Network Approach," International Journal of Electric Power and Energy Systems, Vol. 21, pp. 405-415, 1999.

[7] H.L. Zeynelgil, A. Demiroren, and N.S. Sengor, "The Application of ANN Technique to Automatic Generation Control For Multi-area Power System ," International Journal of Electric Power and Energy Systems, Vol. 24, pp. 345-354, 2002.

[8] J. Talaq and F. Al-Basri, "Adaptive Fuzzy Gain Scheduling For Load Frequency Control," IEEE Transactions on Power Systems, Vol. 14, pp. 145-150, 1999.

[9] C. Indulkar and B. Raj, "Application of Fuzzy Controller to Automatic Generation Control," Electric Machines and Power Systems, Vol. 23, pp. 209-220, Mar. 1995.

[10] D.E. Goldburg, Genetic Algorithms in Search, Optimization, and Machine Learning, Reading, MA:,Addison-Wesley, 1989.

[11] D. Beasley, D.R. Bull, and R.R. Martin, "An Overview of Genetic Algorithms: Part 1, Fundamentals," University Computing, Vol. 15, No. 2, pp. 58-69, 1993.

[12] M. Gen, and R. Cheng, Genetic Algorithms \& Engineering Design, John Wiley \& Sons, Inc., 1997.

[13] M. Mitchell, An Introduction to Genetic Algorithms, Prentice Hall, India, 2002.

[14] K. Ogata, Modern Control Engineering, Prentice Hall of India, New Delhi, 2000. 